\title{
Use of a Team-Based Video Simulation to Complement a Lecture in Motivational Interviewing to Develop Students' Initial Attitudes and Skills
}

\author{
David F. Malewski, PharmD, PhD; Shane P. Desselle, RPh, PhD, FAPhA; Ranjit Kali-Rai, PharmD
}

Touro University California

\begin{abstract}
Background: Motivational interviewing (MI) is increasingly recognized for its patient-centered approach to clinician-patient communication and often effective in evoking appropriate changes in patient behavior. Doctor of Pharmacy (PharmD) programs are increasingly incorporating Ml education; however, doing so represents a challenge regarding availability of both time and labor capital. Case Description: This study reports on the use of a 90-minute software-based simulation and tutorial coupled with a 90-minute lecture in a 3-hour course session. In a subsequent session consisting of several brief interactions with standardized patients (SPs), students reflected upon their strengths and challenges as a result of attempting to apply the MI principles they learned during the educational intervention.

Case Themes: Students' responses to a questionnaire delivered both before and after the simulation and lecture, showed improvements in several attitudinal components related to use of $\mathrm{MI}$, as well as developing self-efficacies in deploying patient-centered communication strategies. A post-intervention survey without students'opportunity to study/prepare saw gains in student knowledge about MI.

Case Impact: The measurements employed to determine student's attitude and knowledge showed good to very good internal consistency reliably based on calculated Cronbach's alpha and KR-20. Student reflections indicated their understanding of MI principles, even though they fell short of implementing them in large part during their encounters with SPS.

Conclusion: Use of a video simulation undergone by teams of PharmD students coupled with a brief lecture might be an effective and efficient way of building a foundation for MI competency among PharmD students where instructors might lack labor capital and significant space in the curriculum.
\end{abstract}

Keywords: Motivational interviewing, patient counseling, self-efficacy, simulation

\section{INTRODUCTION}

Motivational interviewing is increasingly recognized for its potential to promote patient behavior change, including medication adherence. ${ }^{1}$ Motivational interviewing (MI) is a directive, patient-centered counseling style that explores patient ambivalence and attempts to resolve their resistance to change. ${ }^{2}$ The use of open-ended questions and empathy helps patients realize the discrepancy between their current habits and personal goals upon self-reflection, while assuring their self-efficacy and autonomy, and eschewing any attempt to coerce or "trick" them into healthier behaviors and/or choices. The "spirit" of MI is often characterized by the mnemonic "READS" (Roll with resistance; Avoid argumentation; Develop discrepancy; Support self-efficacy). ${ }^{3}$

Much pedagogical literature has focused on $\mathrm{MI}$, with many health professions education programs now incorporating some form within their curriculums. In fact, there is ongoing debate as to whether to require $\mathrm{Ml}$ training as part of medical

Corresponding author: David F. Malewski PharmD, PhD Assistant Professor, College of Pharmacy

Touro University California

1310 Club Drive, Vallejo, CA 94592

Phone: 314-482-5695; Email: dmalewsk@touro.edu school curricula. ${ }^{4}$ The Center for the Advancement of Pharmacy Education (CAPE) outcomes and the Accreditation Council for Pharmacy Education Guidance for Standards 2016 both mention $\mathrm{MI}$ as a communication strategy. The CAPE learning objective 3.6.1 specifically recommends $\mathrm{MI}$ as useful technique for training pharmacy students in how to effectively interview patients. ${ }^{5}$ Similarly, the ACPE Appendix B recommends the use of $\mathrm{MI}$ as a method of communication that employs a patient's self-efficacy as a means of effecting behavior change. ${ }^{6} \mathrm{An}$ overwhelming majority (94\%) of recent graduates of Doctor of Pharmacy (PharmD) programs in North Carolina supported the incorporation of $\mathrm{Ml}$ training in curricula; many of them also stating that it was applicable to current practice, with fewer indicating that they were actually prepared to engage patients with MI. ${ }^{7}$ Another study showed PharmD students integrating $\mathrm{MI}$ as an integral part of conducting patient counseling and education. ${ }^{8}$ Students positively appraised their experience and especially noted the importance of supporting patient selfefficacy as a useful MI principle.

A number of commentary and research papers on motivational interviewing have appeared in the pharmacy education literature during the previous decade. Lupu et al. randomized first-year students into cohorts engaging in written dialogue, peer role-play, or mock patient counseling activities following a motivational interviewing lecture. ${ }^{9}$ The findings showed that students interacting with standardized patients improved their 
ability to conduct pharmacy-related assessments. Goggin et al. established an entire elective course on motivational interviewing. ${ }^{10}$ The course combined lecture with assigned readings and various opportunities for translation of new knowledge, including the requirement to complete six structured out-of-class practice interviews. In a related study, Villaume et al. described a written assignment aimed at facilitating the understanding and utilization of motivational interviewing in dealing with patient ambivalence and resistance. ${ }^{11}$ Students were required to write a script for a working prototype of a virtual patient assigned to them for various activities throughout their curriculum. The authors reported greater interest in and understanding of $\mathrm{MI}$ following this activity.

Bradford et al. described the creation of an introductory $\mathrm{MI}$ module for second-year pharmacy students that was modified to reinforce an initial module in the first-year curriculum. ${ }^{12}$ Overall case scores improved from $81.9 \%$ to $86.9 \%$ during an objective structured clinical examination (OSCE) following the second-year curriculum module. Demonstrating the integration of $\mathrm{MI}$ more longitudinally, Buring et al. described the implementation of $\mathrm{Ml}$ throughout a PharmD curriculum. ${ }^{13}$ Students experiences ranged from introductory lectures to interactions with standardized patients and an OSCE assessment. A cohort of students saw their performance on a role-play exercise improve from a year 1 baseline score of 21.9 (out of 30) to 25.8 by year four of the curriculum. Extending to advanced pharmacy practice experiences (APPEs), Bailey et al. created a $\mathrm{Ml}$ learning module for students on experiential rotations. ${ }^{14}$ During the site-specific rotation students underwent training and were assessed via a patient interview that also included a shadowing phase for them to observe $\mathrm{MI}$ in a real setting. Students' post-training ability scores were judged higher compared to pre-training, and these students indicated positive feedback about the experience. Most recently, Teeter et al. evaluated student use of motivational interviews during an introductory pharmacy practice experience (IPPE) $\cdot{ }^{15} \mathrm{~A}$ unique aspect of this study incorporated student reflections based upon scripted questions that queried students about their use of patient-centered communication during the IPPE rotation. Student reflections were assessed by course instructors using a five-level scheme. Nearly half of the students were found to be reflecting at either of the two higher determined acuity levels of reflection behavior, indicating the development of personal insight and behavior change based on intent for the student to use $\mathrm{Ml}$ in the future. ${ }^{15}$

Student education in other health professions programs seems to have followed similar patterns based upon recent increased amounts of literature on $\mathrm{Ml}$ instruction, including a variety of approaches. Pedagogical interventions have ranged widely in schools of medicine, such as mandatory incorporation of a 4week curriculum taught in small groups to medical students within their third year of the program, ${ }^{16}$ versus a briefer exposure during their first year. ${ }^{17}$ Similarly, another school used videos to educate nutrition students about $\mathrm{MI}$ within their final year. ${ }^{18} \mathrm{~A}$ recent systematic review of $\mathrm{Ml}$ education to medical students, also commenting on education in other health professions, suggested various programs throughout the U.S. have taken a wide approach to the implementation and the assessment of $\mathrm{Ml}$ education. ${ }^{19}$

The incorporation of $\mathrm{Ml}$ education might continue to vary for some time, as individual programs of learning undertake significant overhauls of their curriculums. Until that time, programs aiming to include $\mathrm{Ml}$ education must tailor learning modules into existing curriculums. Accommodating $\mathrm{MI}$ education into the wide variety of curriculum structures could involve significant expenditure of hours and labor capital. Patient simulation videos may serve as an additional tool available for programs lacking in curriculum space and labor capital. ${ }^{20} \mathrm{~A}$ simulation tool can be particularly useful in the didactic component of a curriculum featuring an accelerated block schedule.

The purpose of this study was to evaluate incorporation of an $\mathrm{MI}$ simulation training module in an accelerated block schedule curriculum. The specific objectives were to: (1) evaluate a brief lecture and $\mathrm{MI}$ simulation training exercises on first-year PharmD students' attitudes, self-efficacy, and knowledge of MI; and (2) examine student group reflections regarding their attitudes, knowledge, and self-efficacy after practicing using their newly acquired MI skills on standardized patients (SPs).

\section{CASE DESCRIPTION}

\section{Course Structure}

The course in which the intervention took place is a required part of an accelerated didactic curriculum (less than three years) with courses taught in 3-hour block schedules. The course is provided to first-semester pharmacy students with an emphasis on health systems; however, the course also includes aspects of professional communication, law, and ethics. It approximates a 4-semester credit course and covers a large number of topics. There are no graduate or teaching assistants and no availability of more senior students to assist with "trainthe-trainer" type of educational modalities. Students are placed into ten groups of seven to nine members that are consistent throughout every course in the semester, and these groups can be utilized by course faculty for structured groups discussions (SGDs) and other active learning events.

\section{Motivational Interviewing Content Delivery, Activity, and Practice}

Prior to 2019, the course instructor provided a lecture of approximately two to two and one-half hours on the spirit of motivational interviewing. In 2019, the lecture was pared down to approximately 90 minutes. Post lecture, for the remaining class time, the students separated into their respective SGD groups and worked on the MI simulations, as well as a pre and post-simulations questionnaire. 
The simulations were provided by National Healthcareer Association ${ }^{\circledR}$ (NHA). The MI simulations exist as Module 4 in the Principles of Health Coaching ${ }^{\mathrm{TM}}$ certificate program (NHA, Leawood, Kansas) developed in collaboration with their partner, who specializes in producing simulations of real-life conversations, Kognito ${ }^{\circledR}$ (New York, NY). The software was provided at no cost to the coordinator, so as to pilot it for use in PharmD programs.

The simulation was structured so that it featured five set case scenarios followed by questions and answers. The scenarios were developed with the assistance of pharmacists, pharmacy managers, and technicians for use by a variety of healthcare professionals. It was decided to have the students undertake four of the five scenarios because one was not applicable to their future experiences. Students assumed the virtual role of a health practitioner having a discussion with a patient and family. For a given scenario, the program shows the students a short video where the patient, and sometimes the patient's family, introduced themselves and may provide some initial information. The students would then be presented with several different potential responses that, as the virtual provider, they could use to address the simulated patient and/or patient's family. The simulation program employed algorithms that reacted to each group's choice. Depending upon the selection, the program would take the user down different paths with differing patient responses and differing available provider responses. Thus, the student groups were able to experience relative success or failure in the counseling of the patient entirely dependent upon the choices they made during their virtual interaction. For example, if the students failed to use a strategy of rolling with resistance instead telling the patient that they needed to follow their advice and instructions, then the patient could become more obstinate to the point of walking out of the appointment. Students were encouraged to repeat each scenario several times to compare different communication strategies with the virtual patients; especially if their first interaction resulted in a negative communication outcome with the patient. For example, on repeating the scenario if the students choose a course of action that utilized rolling with resistance and discrepancy building, then they were presented with better opportunities to develop rapport with the patient and work towards more beneficial resolutions and/or courses of action. $\mathrm{Ml}$ is not a zero-sum type endeavor, therefore what is important is developing and using good communication strategies that support open dialog and the free movement of ideas and information back and forth between the provide and patient; i.e. motivational interviewing resides within effective communication strategies rather than being an isolated concept.

Approximately 1 and 2 weeks following the lecture and simulation, the students were given the opportunity to exercise their newly developed, and simulation-practiced, MI skills to role-play as pharmacists with standardized patients. The University maintains a Clinical Skills Laboratory (CSL) staffed and utilized primarily by its College of Medicine. The College of Pharmacy, namely this particular course, makes use of the CSL and its paid actors as SPs. Five groups of students visited the CSL on one day and the other 5 groups on another day. Over the course of two hours, each group had the opportunity to interact in an authentic clinic room individually with each of the five SPs.

The interactions were based upon five separate scripts written by the course instructor and provided to CSL personnel and SPS ahead of time. The SP interactions were scripted to account for five different clinical scenarios and patient types with no specific alignment to the previous MI simulation. For each patient the students were supplied a basic account of the medical record including known medications, conditions, and other normally available information. However, the students were not informed as to the specific reason(s) the patient was visiting the clinic on that day, nor the primary goal of the interaction. Students were expected to adhere to provided rules for engagement, with a different individual student from the SGD group volunteering to act as the primary pharmacist for each of the five patients (i.e., not every student got the opportunity to assume the primary pharmacist role). The student acting as primary pharmacist was afforded one "time out" with each patient encounter to confer with the rest of their group during the seven to eight minute SP encounter. The groups were given approximately two minutes to review the patient's chart. The SP was then brought into the clinic room where the acting pharmacist was given up to seven minutes to consult the patient. With the exception of the one "time out" period, during which the acting student was allowed to strategize how best to communicate with their SP, the acting pharmacist was to proceed as if they were the only other person in the room with the patient. Likewise, the SPs were instructed to respond only to the acting pharmacist. Immediately after each of the five interactions, each group performed a quick debrief of approximately one minute to discuss the interaction. This was followed by a longer debrief of three minutes where each group opened a sealed envelope for the patient they had just counseled. These envelopes contained "key insights and clinical pearls" addressing that particular counseling session. This process was repeated for each of the five SPs.

The course coordinator and a second volunteer faculty were able to observe the students' interaction with the SPs through the use of cameras. Each room was outfitted with cameras and sound allowing observation of one to two groups (of the five) at any one time. The faculty were able to observe four activities; the pre-visit chart review, the primary interaction with the SPS, a quick debrief each group had following the SP seen, and a longer debrief where the students were provided with 'key insights and clinical pearls' about that SP. After the groups had finished meeting with all five SPs, all five student groups met with two course instructors for a larger and more general debrief session. Now that the students had been afforded a 
chance to utilize their MI skills in mock practice they were asked to submit one reflection per group detailing their greatest challenges and strengths in working with the SPs. The students responded to a series of 12 questions eliciting the extent to which various behaviors comported with the spirit of $\mathrm{Ml}$ that they were attempting to employ during their mock counseling sessions. The students were not graded on their responses to the pre-post survey nor for their interactions with the SPs. The students were graded on their reflections about the interactions, in particular, their thoroughness of accounting for positive and negative aspects, perceived application of $\mathrm{MI}$ principles, and detailing what they learned from the experience.

\section{Assessment of Students' Motivational Interviewing-related Attitudes, Knowledge, and Self-Efficacy}

The study involved a pre-post design employing a multicomponent survey to assess students' attitudes, knowledge, and self-efficacy to perform various aspects of MI. The same survey was administered prior to the lecture and then immediately following the interactive video simulation during the same 3-hour block. The study also collected student group reflections following their SP interactions in an effort to discover self-identified strengths and challenges from the students' perspective.

The survey contained three components derived from the literature on the spirit of $\mathrm{MI}$, and specifically from two instruments: the Motivational Interviewing Treatment Integrity $(\mathrm{MITI}-4)^{21}$ and the Behavior Change Counseling Index (BECCI). ${ }^{22}$ Both are used to evaluate or score a participant's actual MI counseling session with a real or standardized patient. The MITI-4 is a more extensive evaluation that gathers information from the evaluator regarding the participants' use of various components of $\mathrm{MI}$, including close-ended questions, abiding by the spirit of $\mathrm{MI}$, respecting patient autonomy, rolling with resistance, etc. Whereas, the $\mathrm{BECCl}$ is briefer, yet attempts to elicit from the evaluator the extent to which the participant was able to begin a patient's (or actor's) path toward behavior change. Questions from the MITI-4 were adapted to help determine the student's self-efficacy regarding their learning and application of the MI principles.

The first component (part one) of the survey contained nine attitudinal questions about MI (See Table 1). Students indicated their level of agreement on a 6-point scale of agreement without a "neutral" scale interval. ${ }^{23}$ Part two of the survey contained 16 objective "test" questions with a definitive correct answer. There were three true/false and 13 multiple choice questions ranging from relatively simple facts about $\mathrm{MI}$ to more complex questions signifying the highest level of $\mathrm{MI}$ performance, along with other questions proposing the best pharmacist response in a hypothetical patient dialogue. Some of the more challenging questions and response choices pertaining to highest level of patient-centered communication were taken directly from the MITI-4 instrument. Others were derived from the $\mathrm{BECCl}$, additional literature, and examination questions from previous iterations of the same health systems/communication course. Part Three of the survey contained nine items measuring students' self-efficacy on a 10point scale of confidence as per Bandura. ${ }^{24}$ Several items were derived from $\mathrm{BECCl}$ and elsewhere in the literature and also inclusive of basic patient-centered communication strategies that had long been taught in the course. Students completed the team-based reflections through the University's Canvas ${ }^{\mathrm{TM}}$ (Instructure ${ }^{\circledR}$, Salt Lake City, UT) learning management system. This study was approved by the Touro University California IRB.

\section{Analysis}

For the purposes of analysis, student response choices for the 16-item objective test after initial data entry were transformed into "correct" (dummy coded as 0) and "incorrect" (dummy coded as 1) responses. All other responses were transcribed directly and treated as ordinal scale values. Reliability analyses employing Cronbach's alpha for the ordinal scales and a KuderRichardson 20 for the objective measures were performed. Differences between pre- and post-scores were determined on the objective component through the use of chi-square tests, whereas independent sample $t$ tests discerned statistical differences on the summed attitude and self-efficacy components. Paired testing was not an option, as the surveys were anonymous and not coded to match pre- and postsurveys per individual student.

The student reflections were read carefully by the course coordinator/primary instructor. There were only ten groups, thus resulting in only ten reflections. As such, there was no attempt at formal content analysis. The approach taken here was to discern the extent to which students pointed out, with deeper reflection, aspects of the MI consultations that could have been performed better in light of the lecture and simulation that they underwent during the week prior.

\section{CASE THEMES}

\section{Student Demographic Characteristics}

Demographic characteristics of individual respondents were not acquired. There were 77 students enrolled in the course. There were 71 students in attendance on the day of the lecture and simulation. There were 68 students who completed the pre-class survey, and 63 students who completed the post-class survey. Some students left prior to taking the post-class survey, as the course session ran a bit over time due to a fire alarm and evacuation during the session that took up nearly 30 minutes of time. Class statistics acquired from the Registrar's Office indicate that of the 77 students, 42 (54.5\%) were male and 35 (45.5\%) were female, and 49 (63.6\%) report English as their primary language, and 28 (36.5\%) report English as a secondary language. Students come from a wide variety of racial/ethnic backgrounds including Asian, Arabic, Persian, Hispanic, Caucasian, and African descent. 


\section{Students' Attitudes Toward MI}

Table 1 provides the mean responses of students pre- and postiterations of the survey. Conceptually, from the principal components analysis, students' attitudes were comprised of three dimensions, including "Practice Setting Considerations" (\#s 7 and 8), "MI Favorability" (\#s 1, 2, 3, and 5) (with some negative loadings), and "MI Experiences" (\#s 4, 6, and 9). Even with multiple dimensions, the overall Cronbach's alpha for the 9-item measure was 0.81 . Following the educational intervention, students were more likely to view $\mathrm{MI}$ as an effective technique to evoke change, while being less likely to indicate that $\mathrm{Ml}$ is a method designed to trick patients and that patients like being told exactly what to do. These differences were in spite of the fact that $\mathrm{Ml}$ attitudes were relatively favorable even for the pre-intervention survey, perhaps given some initial exposure to basic communication concepts and in knowing that $\mathrm{MI}$ was upcoming on their curriculum calendar.

\section{Students' Knowledge of MI Spirit and Principles}

Students' proportion of correct responses to the objective test component of the questionnaire both pre- and postintervention can be found in Table 2. A Kuder-Richardson 20 was calculated at 0.78 for the 16 items, indicative of solid content validity, with high performers consistently answering individual questions correctly more so than low performers. With the possibility of scoring from zero to 16 , the class average was 8.25 for the pre-intervention questionnaire (51.6\%), and 12.92 on the post-intervention questionnaire (80.8\%). Statistical improvements from pre- to post-intervention were observed on the composite and most individual items, with exceptions being some of the more challenging questions. There were improvements on items related to the spirit of $\mathrm{MI}$ (e.g., how to explore ambivalence, roll with resistance, develop discrepancy, support self-efficacy) and on certain pneumonics helpful for remembering how to evoke patient change. Students had difficulty pre- and post- with some questions, such as those attempting to describe the highest level of pharmacist-patient dyadic exchanges.

Students Self-Efficacies for Patient-Centered Communication Table 3 provides student self-efficacy scores pre- and postintervention. A principal components analysis suggested this 9item measure to be uni-dimensional, with a Cronbach's alpha calculated at 0.91 . Students' report of self-efficacies for patientcentered communication underscoring $\mathrm{MI}$ principles were rather high even prior to the class session on MI. This finding may have been a function of students over-estimating their skills or having received prior basic instruction on communication principles. Still, they reported lower selfefficacies for higher-order and more specific Ml components, such as rolling with resistance and exploring patient ambivalence, while reporting higher levels of self-efficacy for some items, such as providing reflecting statements and empathizing. Even with high levels of self-efficacy prior to the intervention, statistically significant improvements were seen on several of the items (e.g., rolling with resistance, addressing patient ambivalence, using open-ended questions) and their sum total.

\section{Student Reflections Following their Group/Team Interactions with SPs}

Students gave seemingly earnest accounts of their performance with the SPs. Table 4 groups their responses into whether they addressed the representative themes of attitude, knowledge or self-efficacy. They acknowledged some things they did well, such as express empathy, but indicated how force of habit had them struggling sometimes even with the lower levels of communication, such as using open-ended questions. They indicated that if they got "on a roll" they would continue with such techniques, but that if they "got in a bind" or sometimes even to start out an encounter, they would think deeply and consciously to avoid resorting to old habits when having a conversation. The reflections supported their awareness of the spirit of $\mathrm{Ml}$ as indicated in their post-intervention knowledge surveys, even if they were not yet able to perform at a high level.

\section{EXPLORATION OF CASE IMPACT}

The results of the study add to the current body of knowledge on motivational interviewing pedagogy. Specifically, that a lecture and patient simulation undergone by teams of students was associated with statistically improved knowledge of, attitudes toward, and self-efficacy in performing MI. Likewise, reflections about their practice interactions with standardized patients indicates that student teams were able to recognize deficiencies in their actual performance in their first exposure to an MI activity using SPs.

Keifenheim et al. conducted a pilot evaluation of MI education using a blended learning approach that combined videos with traditional lecture. ${ }^{25}$ Students became engaged with the topic and were interested in learning more, even while their actual performance required improvement. Indeed, the transfer of learning to practice is complex, as evinced by Norris et al. in an attempt to teach $\mathrm{MI}$ to undergraduate occupational therapy and physiotherapy stuents. ${ }^{26}$ In a qualitative evaluation component of their study where they compared focus group results with student "post-it" notes in a post-training questionnaire, Norris et al. uncovered two themes from the student perspective in regard to their learning: (1) desire to abide by the spirit of $\mathrm{MI}$, and (2) facilitators and barriers to learning. The current study corroborated those findings wherein student reflections indicated a desire to perform better. Informally, students told the primary instructor that they would "get giddy" when they thought they had done something well, but also indicated that it was so difficult to avoid closed questions and leading the patient once they encountered difficulty. Cook et al. reflected on 10 years of $\mathrm{MI}$ interprofessional education among various health professions at one institution and commented that $\mathrm{MI}$ training is rife with challenges, but provides myriad opportunities for student 
critical evaluation, even if $\mathrm{MI}$ prowess has fallen below expectations established by the instructors. ${ }^{27}$

As such, this classroom educational intervention provides evidence for pharmacy educators in a compact curriculum and/or one that awaits transition to accord MI more credit hours and perhaps more labor capital, that a lecture and simulation at the very least improve knowledge and awareness. Other studies have suggested that brief exposure to $\mathrm{MI}$ concepts can do the same. ${ }^{28,29}$ Longitudinal and repeated exposure, preferably including SP encounters, will surely be that much more helpful to students. However, though there is a need to incorporate new findings, such experiences are not easy to implement, even during curriculum transition. This is especially true given that different disciplines within pharmacy often compete with each other for more credit hours. MI would seem to be an area ripe for interprofessional collaboration and to become a wider component of high-stakes or similar types of summative assessments.

This study saw student gains in certain attitudes and selfefficacy, even in spite of rather high self-efficacies reported on the pre-intervention survey. Perhaps students overestimate their communication ability. It would have been interesting to discern students' thoughts of their initial communication selfefficacies AFTER taking part in the SP exercises. However, the fact that students initially rated their ability to roll with resistance and explore ambivalence (two higher order levels of $\mathrm{MI})$ lower than to express empathy suggests that the students had at least some level of grounding to enter into this educational session. It was also encouraging that the educational intervention was associated with certain attitudes, in particular, such as a lesser likelihood to seeing MI as a way to trick patients and lesser likelihood to agree that patients like being told exactly what to do.

This study has several limitations. Some student questionnaire respondents might have provided answers to attitudinal and self-efficacy questions that they thought the instructors/researchers were looking for, or that which they perceived as more socially acceptable. Researchers did not gather identifying information and thus were not able to perform paired statistical tests to discern differences on individual students pre- and post-intervention. The postintervention questionnaires were completed following both a lecture and an $\mathrm{Ml}$ simulation. The individual contribution of each component of the intervention cannot be determined from the study design. Knowledge, positive attitudes, and selfefficacy do not necessarily translate directly into higher levels of performance. Future research should determine the relationship between knowledge, self-efficacy, and attitudes with actual MI performance. The effect of simulation alone should be determined not only on these constructs, but also as a building block to performance following additional exposure to varied pedagogical learning modalities; and student effectiveness in Ml even in summative OSCE-type environments should be evaluated against their ability and their actual use of $\mathrm{MI}$ as practicing pharmacists. Future efforts may be warranted to examine the development of a new comprehensive instrument capable of measuring knowledge and ability to apply MI principles, especially as has implications for a students' actual abilities. Consideration should also be given to evaluations and further development of student's MI and related knowledge after the exposure. While this method of education/simulation is less labor intensive, further study is needed to determine the lasting impact on student's knowledge, attitudes and communication skills; i.e the investment is worthwhile as an educational intervention, even though it is less resource intensive.

\section{CONCLUSION}

This study saw an improvement in the attitudes, self-efficacies, and knowledge of first-year PharmD students toward motivational interviewing following a brief educational intervention involving a 90-minute lecture and 90-minute simulation. Awareness of the need to improve abilities in patient-centered communication was evident in subsequent student reflections following team-based interaction with standardized patients. These findings could be helpful to educators seeking efficient mechanisms of delivering MI content in curriculums without an abundance of available hours and/or without much labor capital expertly trained in MI availed for their courses.

\section{Conflicts of Interest: None \\ Funding/support: None}

\section{REFERENCES}

1. Palacio A, Garay D, Langer B, Taylor J, et al. Motivational interviewing improves medication adherence: a systematic review and meta-analysis. J Gen Int Med. 2016; 31(8):929-40. DOI: 10.1007/s11606-016-3685-3.

2. Miller W, Rollnick SR. Motivational Interviewing: Preparing People to Change, $2^{\text {nd }} e d$. New York: The Guidlford Pres; 2002.

3. Levensky ER, Forcehymes A, O'Donohue WT, Beitz K. Motivational interviewing: An evidence-based approach to counseling helps patients follow treatment recommendations. Am J Nurs. 2007; 107(10):50-58. DOI: 10.1097/01.NAJ.0000292202.06571.24.

4. Shemtob L. Should motivational interviewing training be mandatory for medical students? Med Educ Online. 2015; 21:31272. DOI: 10.3402/meo.v21.31272.

5. Medina MS, Plaza CM, Stowe CD, Robinson ET, et al. Center for the Advancement of Pharmacy Education (CAPE) Educational Outcomes 2013. Am J Pharm Educ. 2013; 77(8):162. DOI: 10.5688/ajpe778162.

6. Accreditation Council for Pharmacy Education. Guidance for the accreditation standards and key elements for the professional program leading to the Doctor of Pharmacy degree. Available at: https://www.acpeaccredit.org/pdf/GuidanceforStandards2016FINAL.pdf. Accessed: August 20, 2021. 
7. Battise D, DeValve MJ, Marlow D, Beasley B, Miller S. Need and desire among pharmacy practitioners for motivational interviewing to be incorporated into pharmacy curricula. Curr Pharm Teach Learn. 2014; 6(4):386-92. DOI: 10.1016/j.cptl.2014.02.019.

8. Owensby JK, Kavookjian J. Pharmacy students' perceptions of the usefulness of motivational interviewing and the use of mobile health applications on patient counseling in the future. Curr Pharm Teach Learn. 2017; 9(4):568-75. DOI: 10.1016/j.cptl.2017.03.019.

9. Lupu AM, Steward AL, O'Neil C. Comparison of active learning strategies for motivational interviewing skills, knowledge, and confidence in first-year pharmacy students. Am J Pharm Educ. 2012; 76(2):28. DOI: 10.5688/ajpe76228.

10. Goggin K, Hawes SM, Duval ER, Spresser CD, et al. A motivational interviewing course for pharmacy students. Am J Pharm Educ. 2010; 74(4):70. DOI: 10.5688/aj740470.

11. Villaume WA, Berger BA, Barker BN. Learning motivational interviewing: Scripting a virtual patient. Am J Pharm Educ. 2006; 70(2):33. DOI: 10.5688/aj700233.

12. Stafford RA, O'Brien CE, Franks AM. A communications module to reinforce motivational interviewing. Curr Teach Pharm Learn. 2019; 11(7):843-48. DOI: 10.1016/j.cptl.2019.04.014.

13. Buring SM, Brown B, Kim K, Heaton P. Implementation and evaluation of motivational interviewing in a Doctor of Pharmacy curriculum. Curr Teach Pharm Learn. 2011; 3(2):78-84. DOI: 10.1016/j.cptl.2011.01.005.

14. Bailey L, Curington R, Brown B, Hegener M, Espeal M. Motivational interviewing education: Creation and assessment of a learning module implemented among advanced pharmacy practice students. Curs Pharm Teach Learn. 2017;9(6):786-93. DOI: 10.1016/j.cptl.2017.06.007.

15. Teeter B, Stafford R, Payakachat N, Ried J, et al. Student pharmacists' use of patient-centered communication skills during an introductory pharmacy practice experience. Am J Pharm Educ. 2019; 83(8):7244. DOI: 10.5688/ajpe7244.

16. Bell K, Cole BA. Improving medical students' success in promoting health behavior change: a curriculum evaluation. J Gen Int Med. 2008; 23(9):1503-6. DOI: 10.1007/s11606-008-0678-x

17. Tully MA Gilliland AE, Cupples ME. Medical students' confidence in performing motivational interviewing after a brief training session. Med Teach. 2008; 30(4):438-9. DOI: 10.1080/01421590701769597.
18. Simper TN, Breckon JD, Kilner K. Effectiveness of training final-year undergraduate nutritionists in motivational interviewing. Patient Educ Counsel. 2017; 100(10):18981902. DOI: 10.1016/j.pec.2017.05.016.

19. Kaltman S, Tankersley A. Teaching motivational interviewing to medical students: A systematic review. Acad Med. 2019. [Epub ahead of print]. DOI: 10.1097/ACM.00000000000003011.

20. Chang YP, Cassalia J, Warunek M, Scherer Y. Motivational interviewing training with standardized patient simulation for prescription opioid abuse among older adults. Perspect Psychatr Care. 2019; 55(4):681-89. DOI: 10.1111/ppc.12402.

21. Moyers TB, Rowell LN, Manuel JK, Ernst D, Houck JM. The Motivational Interviewing Treatment Integrity code (MITI 4): Rationale, preliminary reliability, and validity. $J$ Subst Abuse Treat. 2016; 65(6):36-42. DOI: 10.1016/j.jsat.2016.01.001.

22. Lane $\mathrm{C}$, Huws-Thomas M, Hood K, Rollnick S, et al. Measuring adaptations of motivational interviewing: the development and validation of the behavior change counseling index (BECCI). Patient Educ Couns. 2005; 56(2):166-73. DOI: 10.1016/j.pec.2004.01.003

23. Garland R. The mid-point range on a rating scale: Is it desirable? Market Bull. 1991;2(1)66-70. Available at: https://www.rangevoting.org/MB V2 N3 Garland.pdf. Accessed: August 20, 2021.

24. Bandura A. Self-efficacy: Toward a unifying theory of behavioral change. Psychol Rev. 1977; 84(2):191-216. DOI: 10.1037//0033-295x.84.2.191.

25. Keifenheim KE, Velen-Schurian K, Fahse B, Erschens R, et al. "A change would do you good": Motivational interviewing using a blended-learning approach-A pilot evaluation. Patient Educ Couns. 2019; 102(4):663-69. DOI: 10.1016/j.pec.2018.10.027.

26. Norris M, Eva G, Fortune J, et al. Educating undergraduate occupational therapy and physiotherapy students in motivational interviewing: the student perspective. BMC Med Educ. 2019; 19(1):117. DOI: 10.1186/s12909-019-1560-8.

27. Cook PF, Manzouri S, Aagaard L, O'Connell L, et al. Results from 10 years of interprofessional training on motivational interviewing. Eval Health Prof. 2017; 40(2):159-79. DOI: 10.1177/0163278716656229.

28. Brown RL, Oriel K. Teaching motivational interviewing to first-year students. Acad Med. 1998; 73(5):589-90. DOI: 10.1097/00001888-199805000-00055.

29. Cheret A, Durier C, Noel N, Bourdic K, et al. Motivational interviewing training for medical students: A pilot prepost feasibility study. Patient Educ Couns. 2018; 101(11):1934-41. DOI: 10.1016/j.pec.2018.06.011. 
Table 1. Attitude toward Motivational Interviewing Items and Mean Responses

\begin{tabular}{lll}
\hline Item & Pre $^{a}$ & Post $^{a}$ \\
& $n=68 \quad n=6$ & $n$
\end{tabular}

1. Motivational interviewing is an effective method to promote patient behavior change. ${ }^{b}$

$4.88 \pm 0.91 \quad 5.66 \pm 0.51$

2. Motivational interviewing isn't needed, because patients think that reflecting back to them is silly. ${ }^{b}$

$2.18 \pm 1.00$

$1.74 \pm 0.99$

3. A pharmacist does not have enough time to utilize motivational interviewing on patients.

$3.11 \pm 1.31$

4. Motivational interviewing is a type of skill that you are born with.

$1.87 \pm 0.89$

$1.73 \pm 1.09$

5. I like the idea of using motivational interviewing to evoke patient behavior change. ${ }^{b}$

$4.72 \pm 0.97$

$5.32 \pm 0.85$

6. Patients like being told exactly what to do by a practitioner to promote healthy lifestyles. ${ }^{\text {b }}$

7. Motivational interviewing is better for use by nurses and physicians than by pharmacists.

$2.76 \pm 1.32$

$2.89 \pm 1.44$

8. Motivational interviewing should only performed in a clinic or hospital setting, rather than in retail or ambulatory care.

9. Motivational interviewing is a pretty neat way to trick patients into getting them to do the right thing. ${ }^{b}$

a Mean \pm standard deviation, as self-reported on a 6-point, Likert-type scale ranging from $1=$ Completely Disagree, to $6=$ Completely Agree

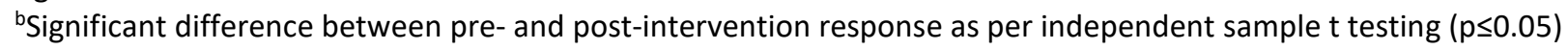


Table 2. Objective knowledge score on "test" items regarding motivational interviewing (\% correct)

Item

Pre $^{\mathrm{a}} \quad$ Post $^{\mathrm{a}}$

$n=68 \quad n=63$

1. Motivational interviewing assumes that the patient is already prepared to make

85.4

Behavioral changes. ${ }^{b}$
a. True
b. False*

2. Motivational interviewing explores a patient's potential ambivalence toward a behavior. ${ }^{b}$

$81.3 \quad 100.0$

a. True* b. False

3. Motivational interviewing encourages patients to express their OWN reasons for concern with their lifestyle behaviors and reasons for/against change. ${ }^{b}$

a. True* b. False

$81.8 \quad 100.0$

4. Which of the following is true about leading the conversation in motivational interviewing?

a. It is best to lead the patient conversation because the patient knows little about their disease state and their medicines

b. It is best to lead the patient conversation because it provides you an opportunity to demonstrate your knowledge, which is key to enhancing customer loyalty

c. It is best to avoid leading the patient conversation because this reduces the likelihood that the patient is involved in decision-making*

$\mathrm{d}$. It is best to avoid leading the patient conversation because the patient will be more empathetic toward you

5. Given the following scenario, which motivational interviewing principle does this example display? ${ }^{\mathrm{b}}$

Pharmacist: "Last time we met, we discussed ways you can start eating food with less unhealthy fat. How are you coming along with that?"

Patient: I knew you would ask that in this appointment. I am tired of people getting on my case about unhealthy eating. I don't understand why I have to change my diet. I eat small portions, anyway.

Pharmacist: "It can be frustrating when all of a sudden you have to make lifestyle changes, especially changes in eating habits. It's great you're eating small portion sizes. May I tell you what concerns me?"
a. Roll with resistance*
b. Express empathy
c. Avoid argumentation
d. Develop discrepancy
e. Support self-efficacy

6. Tammy Woo is a 57-year-old woman who comes to your pharmacy to pick up her prescription for metoprolol, a medication for high blood pressure. You begin a conversation with her because you see a pack of cigarettes on top of her purse.

In discussing smoking cessation with Tammy Woo which one of the following statements best expresses the spirit of motivational interviewing (MI)?

a. "I see that you are still smoking, despite what the doctor probably advised you. You should let me work with you to help you quit".

b. "It looks as if your blood pressure is still high; what do you know or have been told about things you can do to help lower it?"*

c. "I understand that this medical problem has been hard for you; let me tell you some ways you can lower your blood pressure."

d. "Quitting smoking is hard, but it really is important that you make changes to prevent complications from heart disease." 
e. "Looks like you're still smoking. How do you expect the medication to improve your high blood pressure problem if you're not willing to."

7. Given the scenario below, which Motivational Interviewing principle does this example display? ${ }^{b}$

Patient: "I am tired of everyone telling me that to be a good grandfather, I have to eat healthy and take care of myself."

Pharmacist: "It sounds like you are frustrated with your family's concerns. On the one hand, based on what you are telling me, it sounds like you have two important goals in your life right now: (1) to be a good grandfather and (2) to be in your grandchild's life. But on the other hand, you've told me that you like to smoke and enjoy eating foods that are raising your cholesterol. What impact do you think your decision to keep smoking and not change what you eat will have on your desire to be around for your grandchildren?"

a. Roll with resistance, b. Express empathy, c. Avoid argumentation, d. Develop discrepancy*, e. Support self-efficacy

8. Which of the following statements best illustrates the concepts of supporting self-efficacy?

a. "Come on. You can do it if you really try."

b. "I know lots of other people who did it."

c. "It sounds like you are concerned that you will not be able to do it".

d. "Looks like you've found a way to get on the right track".*

e. "If anyone can do it, you can".

9. Which of the following would indicate the highest level of motivational interviewing being performed?
a. Clinician fosters collaboration and power sharing so that the patient's ideas are the only ones incorporated into the treatment plan.
b. Clinician actively fosters and encourages power sharing in the interaction in such a way that the patient's ideas substantially influence the nature of the session.*
c. Clinician actively assumes the expert role for the majority of the interaction with the client.
d. Clinician incorporates client's goals, ideas and values but is careful not to overly deepen the patient's contribution to the interview.
e. Clinician responds to opportunities to collaborate with humorous anecdotes.

10. Which of the following is NOT a type of reflection? ${ }^{b}$

a. Mimicking*, b. Feeling, c. Reframing, d. Double-sided, e. Amplified

11. OARS in motivational interviewing includes all of the following techniques EXCEPT: ${ }^{b}$

a. Overtures to the patient*, b. Assessment, c. Reflection, d. Summaries

12. The 5 principles of Motivational Interviewing include: ${ }^{b}$

a. Express empathy, b. Roll with resistance, c. Avoid argumentation, d. $a$ and $b$

e. $a, b$, and $c^{*}$

13. Stating to the patient, "You did a great job parking further from the office today. This will help you meet your goal of 10,000 steps per day," is an example of:

a. Rolling with resistance, b. Empathizing, c. Affirmation*, d. OARS

e. Avoiding argumentation

14. In this stage of motivational interviewing, practitioners set the foundation for the relationship with their patients. ${ }^{b}$

a. Engage*, b. Evoke, c. Focus, d. Plan

15. Change talk can be elicited through several steps and can be remembered using the mnemonic: ${ }^{b}$

a. OARS, b. HELP ME, c. DARN CAT*, d. PATIENCE, e. SILLY GUY 
16. Which of the following represents the highest level of clinician performance when attempting to evoke patient change?

a. Clinician is accepting of client's own reasons for change and ideas about how change should happen when they are offered in the interaction. Does not attempt to educate or direct if client resists.

b. Clinician shows modest interest in patient's own reasons for change and how change should occur. Offers similar information and education provided to other patients.

c. Clinician actively provides reasons for change, or education about change, without needing to know the patient's knowledge, efforts, and motivation.

d. Clinician relies on education and information-giving at the expense of exploring client's personal motivations and ideas.

e. Clinician works proactively to evoke client's own reasons for change and ideas about how change should happen.*

${ }^{*}$ Correct answer

apre- and post survey percentage of correct responses by students

bSignificant difference between pre- and post-intervention as per chi-square testing $(p \leq 0.05)$ 
Table 3. Self-efficacies for various aspects of patient-centered communication

\begin{tabular}{|c|c|c|}
\hline Item & $\begin{array}{l}\text { Pre }^{a} \\
n=66\end{array}$ & $\begin{array}{l}\text { Post }^{a} \\
n=64\end{array}$ \\
\hline 1. Provide effective reflective statements back to the patient. ${ }^{b}$ & $6.75 \pm 1.75$ & $7.55 \pm 1.57$ \\
\hline 2. Roll with a patient's resistance to your recommendations. ${ }^{\text {b }}$ & $5.92 \pm 1.19$ & $7.27 \pm 1.93$ \\
\hline 3. Avoid use of a knowledge-centric, paternalistic style of communication. & $6.50 \pm 2.11$ & $7.12 \pm 1.94$ \\
\hline 4. Address a patient's ambivalence about adhering to their medication. ${ }^{b}$ & $6.59 \pm 1.64$ & $7.37 \pm 1.55$ \\
\hline 5. Apply all aspects of motivational interviewing for various types of patients. & $6.25 \pm 1.94$ & $7.05 \pm 1.76$ \\
\hline 6. Accurately assess a patient's stage of change and tailor your message to them. & $6.77 \pm 1.64$ & $7.18 \pm 1.43$ \\
\hline $\begin{array}{l}\text { 7. Employ open-ended questions when encountering a patient who is resistant to } \\
\text { previously recommended lifestyle changes. }{ }^{b}\end{array}$ & $6.92 \pm 1.80$ & $7.58 \pm 1.76$ \\
\hline $\begin{array}{l}\text { 8. Work with patients to develop an effective and mutually agreed upon treatment } \\
\text { plan. }\end{array}$ & $7.39 \pm 1.74$ & $7.67 \pm 1.49$ \\
\hline $\begin{array}{l}\text { 9. Empathize with patients with poor health choices who are frustrated with } \\
\text { hearing advice. }\end{array}$ & $7.30 \pm 1.82$ & $7.63 \pm 1.62$ \\
\hline
\end{tabular}

Sum $^{b}$

$60.48 \pm 12.54 \quad 66.47 \pm 12.33$

apre- and post-education survey response mean and standard deviation, on a Likert-type scale of confidence ranging from 1 to 10.

${ }^{b}$ Significant difference between pre- and post-intervention response as per independent sample $t$ testing $(p \leq 0.05)$ 
Table 4. Attitude, Knowledge, and Self-Efficacy-related Quotes from Students' Group Reflections

\section{Attitude:}

"We knew better, but it was just soooooo hard not to start the session with closed questions like "Do you know what this medication is for?".

"We thought we knew what to do, but when any of us got in a bind, we start telling the patient what to do."

[Referring to an example of not respecting patient autonomy]. "We told Anthony [one SP name] that we respected his religious beliefs then condescended to him. Would have been better to reflect his concerns back and figure out how to incorporate this into his adherence."

[Referring to asserting authority]. "We kept telling Elena [one SP name] that she needed to have a healthy lifestyle. We didn't give her a chance to explore for herself how certain things would allow her to feel better."

"These patients were tough. We know that not every patient will be like this, but some of them will be. We know that we need more practice."

\section{Knowledge:}

[Referring to exploring ambivalence]. "With Jack [one SP name], we just kept telling him that it was good that he exercised and took vitamins. We didn't ask him much of anything and I guess that's why we never really found out what was wrong with his situation."

“Mary Lou [one SP name] was angry. She came in angry. She left still kinda angry. I think there's things we could have done to make her happy, but we're not sure. Some people are just going to be angry. But we understand that we need to help patients see the light and it doesn't really matter if they are angry or not."

\section{Self-Efficacy:}

[Referring to developing discrepancy]. "George [one SP name] came in not wanting to hear anything about his smoking. By the time he left, he at least said he was going to give it some thought. I think we helped him realize that he might want to keep smoking but maybe others who care for him don't want him to. We were happy with how this one turned out."

"One thing I think we did well was to reflect back the patients' concerns. It wasn't easy. It's not something we do in our usual conversations, but we were very conscious about doing so. And for some of the patients, this seemed to work pretty well."

"We realize that with Elena, we did not take the opportunity to compliment her or acknowledge that she had already cut her smoking in half. She must have thought, 'Wow, I can't get a break from these doctors and pharmacists always hounding me'. This made us think about how we feel when a friend or a parent refuses to acknowledge positive steps we've taken in our own lives." 